\title{
El patrimonio paleontológico: valorización y simbolismo de un pasado desconocido
}

Francisco José Casado Pérez | maestro en conservación y restauración de bienes culturales inmuebles, México

URL de la contribución <www.iaph.es/revistaph/index.php/revistaph/article/view/4140>

En Las formas del olvido, Marc Augé asevera: "dime qué olvidas y te diré quién eres" (1998: 24), aludiendo al sentido vital del olvido en el ciclo mnemónico; sin embargo, ¿qué podría decirse del olvido de lo desconocido? De lo que no está en los registros más antiguos; de aquellos tiempos en que la vida inició: lo paleontológico.

Cuando el tiempo se hizo tiempo, se trazaron en el mundo las líneas continentales y los ambientes, así como los perfiles topográficos en el mar y la tierra. Desde ese momento, los seres microscópicos comenzaron los ciclos de la vida a través del proceso evolutivo hasta antes de los primeros homínidos, aquello es la paleontología. Por tal motivo, si ésta se encuentra directamente relacionada con la historia misma de la tierra, y por consiguiente con la del hombre y su patrimonio, ¿por qué se trata con cierta distancia a la paleontología en la circunstancia patrimonial, si todo está convenido en un mismo tiempo y espacio?

En una impresión inmediata puede enfocarse la respuesta al factor primordial en la ecuación del patrimonio: la presencia humana. Esto debido a que dicho aspecto es un hecho netamente humano, desde la singularización (XIRAU, 1953: 73), hasta la valorización y protección (CARRETÓN, 2016). Sin embargo, ante las premisas de un mundo azorado por el mismo factor determinante que hace circular los tiempos del olvido a marchas forzadas, es imperante incentivar la reflexión sobre nuestros alrededores; de aquello que singularizamos y de lo que pretendemos proteger; de esta urgencia ontológica que "ya no se refiere a la identidad sino al ser; y tampoco es ya: ¿¿Quién soy?’, sino ¿¿Qué soy?’” (AUGÉ, 1998: 31). Enjuiciar el reconocimiento, sus bemoles objetivos, subjetivos; sus jerarquías y juicos para protegerlos y trans- mitirlos a la vida presente y futura (CASADO PÉREZ, 2017: 57). En síntesis, sentarnos a discutir -perpetuamente- la naturaleza misma de la idea -y concepto- de lo que es patrimonio y el modo en que la paleontología se valora, e inclusive, se simboliza en esta.

El motivo parte desde la triada de la sostenibilidad: ambiente, economía y sociedad. En los primeros dos rubros, históricamente en algunos países como México, la paleontología ha representado un punto de inflexión para las ciencias extractivas, en el hallazgo y manufactura de distintos productos, impactando en la tercera esfera con la gestación y proliferación de conjuntos urbano-arquitectónicos, el desarrollo de estructuras socio-culturales, entre otros efectos subsecuentes que nos llevarán, en el ánimo del uróboros, de vuelta al origen; de la transformación -¿o la humanización?- del paisaje natural, saltando al clima y sus efectos en las otras esferas y así hasta el final, frenando la visión ilusoria del ad infinitum.

Por consiguiente, habría que preguntar: ¿qué valor(es) representa la paleontología hoy en día? Nuevamente podemos utilizar la base de la sostenibilidad, por sus capacidades vinculatorias: del ambiente con la figura del paisaje natural patrimonial; de lo económico como parámetro para el desarrollo teórico-práctico de técnicas, métodos y sistemas no invasivos o destructivos para la recopilación y conservación de la información en los estudios patrimoniales de lo arqueológico, histórico, artístico y sobre todo, paleontológico.

Finalmente, en lo social, es donde se requerirá el mayor esfuerzo, debido al reto de superar el desconocimiento de qué es y qué representa la paleontología, hecho que ha repercutido evidentemente en la determinación nor- 
a debate El marco legal para la protección del patrimonio paleontológico. ¿Qué pasa en tu comunidad?

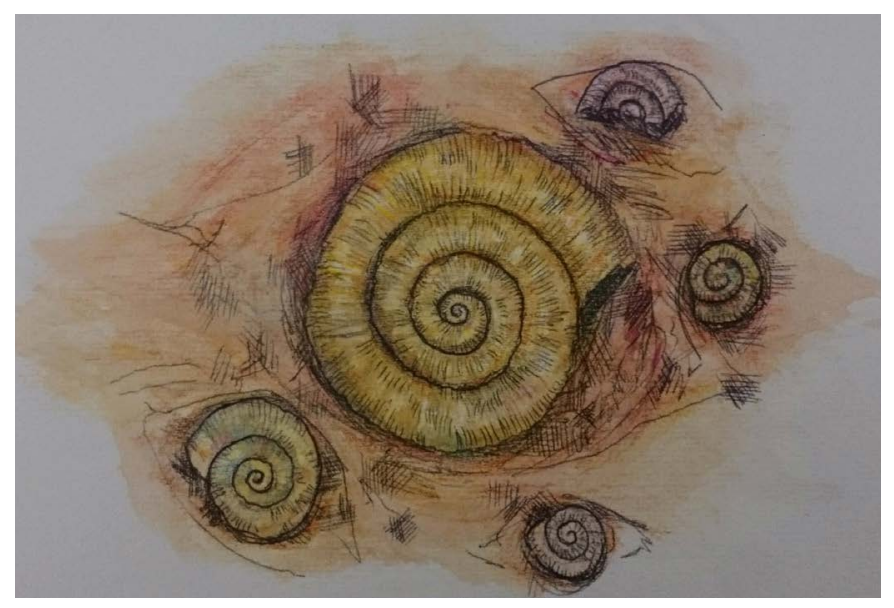

"Mirada paleontológica", 2018. Técnica: Lápiz acuarelable y tinta. 17×24,5 cm (papel para acuarela $160 \mathrm{~g} / \mathrm{m} 2$ ) | dibujo Francisco Casado

mativa, como apunta Alcalá: “...mientras quienes tienen la responsabilidad de gestionar este patrimonio no dispongan de los recursos independientes apropiados o bien establezcan consultas de amplio espectro, será difícil tomar decisiones objetivamente defendibles" (1999: 48) y por tanto, "Ya va siendo momento de que todos seamos conscientes de las normas que afectan a nuestro elemento primordial de trabajo [paleontológico, histórico, contemporáneo, arqueológico, inmaterial, entre otros] [...] y de que -si no las compartimoshagamos lo posible por mejorarlas, en lugar de quedar poseídos por arrebatos de indignación" (Ídem). Es hora de cuestionar más atrás y más allá del tiempo del hombre.

Si a costa del olvido se subleva un esplendor, "[...] extraña cualidad de los instantes en los que el presente se libera del pasado sin dejar transparentar aún nada del futuro que origina su movimiento" (AUGÉ, 1998, 96), en lo desconocido de la paleontología también se encuentra una riqueza similar, como anotan Carreño y Montellano-Ballesteros (2005: 144): "A pesar de las nuevas tecnologías, muchas áreas permanecen, actualizadas sí, pero con el mismo valor de antaño. El peso de los fósiles como indicadores de edad no ha podido ser superado. De ellos depende una parte de nuestra economía $y$, por ello, debemos seguir promoviéndolos."
De tal forma que la paleontología simboliza el eslabón oculto de la espiral humana. Es el lenguaje que nos (re) conecta con el origen mismo. Hecho por el cual requiere una escala equitativa de promoción, fomento e incentivación en la multidisciplinareidad y la transversalidad a través de la figura de motor para desarrollo de la ciencia, la economía, el ambiente y sobre todo la sociedad, tanto actual como venidera. Son estas lecturas las que nos llevarán a darle un sentido real y contemporáneo a lo humano, así como a la naturaleza, alargando un poco más la línea del verdadero final.

\section{BIBLIOGRAFÍA}

- ALCALÁ, L. (1999) Reflexiones acerca de la protección del patrimonio paleontológico. Coloquios de Paleontología[enlínea], vol. 50, 1999, pp. 45-51, Universidad Complutense de Madrid <http://revistas.ucm.es/index.php/COPA/article/view/COPA 9999110045A/29549> [Consulta: 25/03/18]

- AUGÉ, M. (1998) Las formas del olvido. México: Editorial Gedisa, 1998

- CARREÑo, A. L.; MONTELlano-BAllesteros, M. (2005) La Paleontología mexicana; pasado, presente y futuro. Boletín de la Sociedad Geológica Mexicana [en línea], tomo LVII, n. ${ }^{\circ} 2$, 2005, pp. 137-147 <http://boletinsgm.igeolcu.unam. $\mathrm{mx/bsgm/vols/epoca04/5702/(2)Carreno.pdf>} \mathrm{[Consulta:} \mathrm{28/03}$ /18]

- CARRETÓN, A. (2016) El patrimonio paleontológico ¿Es patrimonio realmente? [en línea] Patrimonio Inteligente <http:// www.patrimoniointeligente.com/patrimonio-paleontologico/> [Consuta: 22/03/18]

- CASAdo PÉREZ, F. J. (2017) Principios y criterios para la valorización y conservación de la vivienda modernista en la ciudad de México. Tesis de maestría en Conservación y Restauración de Bienes Culturales Inmuebles. Trabajo inédito

- XIRAU, R. (1953) Sentido de la presencia. México: Fondo de Cultura Económica (FCE), 1953 (Ensayos, Colección Tezontle) 